\title{
From the Bureau of Threats and Opportunities
}

Wishes are catacombs-built for loss and stain-fast, they crumble overnight (of a sudden). So he lands on Yulee by the border at last. He clutches his temples not without drama, but it feels good. The children are outside screaming, sometimes fire and sometimes liar and sometimes fire and liar at the same time. Not his children. There's a long-haired man eating a mango on the avenue-six weeks in the clean white clink. (He wishes he was Dutch again and then regrets it.) How about that for cadenza embellishment? This will be his summer of white horses. Even in the city, six white horses. Life is rough on the streets of the city and life is soft in the circles of the suburbs. Real men wear belts. If he's dead he won't smell her towel again. She would be sole executrix of the proving of 700 dollars, the falcon's yellow ass-feathers and a Fantasia for Keyboard with forty hands, also featuring melodic flourish. 